\title{
Association between Air Pollution and Emergency Room Visits for Atrial Fibrillation
}

\author{
Angelo G. Solimini ${ }^{1, *}$ and Matteo Renzi ${ }^{2}$ \\ 1 Department of Public Health and Infectious Diseases, Sapienza University of Rome, Piazza A. Moro 5, \\ 00185 Roma, Italy \\ 2 Department of Epidemiology, Lazio Regional Health Service, ASL Rome 1, 00147 Rome, Italy; \\ m.renzi@deplazio.it \\ * Correspondence: angelo.solimini@uniroma1.it; Tel.: +39-329-072-2643
}

Received: 14 March 2017; Accepted: 16 June 2017; Published: 20 June 2017

\begin{abstract}
Despite the large prevalence in the population, possible factors responsible for the induction of atrial fibrillation (AF) events in susceptible individuals remain incompletely understood. We investigated the association between air pollution levels and emergency department admissions for AF in Rome. We conducted a 14 years' time-series study to evaluate the association between the daily levels of air pollution (particulate matter, $\mathrm{PM}_{10}$ and $\mathrm{PM}_{2.5}$, and nitrogen dioxide, $\mathrm{NO}_{2}$ ) and the daily count of emergency accesses for AF (ICD-9 code: 427.31). We applied an over-dispersed conditional Poisson model to analyze the associations at different lags after controlling for time, influenza epidemics, holiday periods, temperature, and relative humidity. Additionally, we evaluated bi-pollutant models by including the other pollutant and the influence of several effect modifiers such as personal characteristics and pre-existing medical conditions. In the period of study, 79,892 individuals were admitted to the emergency departments of Rome hospitals because of $\mathrm{AF}$ (on average, 15.6 patients per day: $\min =1$, $\max =36$ ). Air pollution levels were associated with increased AF emergency visits within $24 \mathrm{~h}$ of exposure. Effect estimates ranged between $1.4 \%$ $(0.7-2.3)$ for a $10 \mu \mathrm{g} / \mathrm{m}^{3}$ increase of $\mathrm{PM}_{10}$ to $3 \%$ (1.4-4.7) for a $10 \mu \mathrm{g} / \mathrm{m}^{3}$ increase of $\mathrm{PM}_{2.5}$ at lag $0-1$ day. Those effects were higher in patients $\geq 75$ years for all pollutants, male patients for $\mathrm{PM}_{10}$, and female patients for $\mathrm{NO}_{2}$. The presence of previous cardiovascular conditions, but not other effect modifiers, increase the pollution effects by $5-8 \%$ depending on the lag. This study found evidence that air pollution is associated with AF emergency visits in the short term.
\end{abstract}

Keywords: air pollution; atrial fibrillation; time series; cardiac arrhythmias

\section{Introduction}

Epidemiological evidences of the association between air pollution and cardiovascular diseases (CVD) have been growing in the last few decades [1-3]. Pooled estimates of the percent increase in CVD mortality, derived from meta-analyses and multiple city studies, range between 0.6 and 1.4 for any $10 \mu \mathrm{g} / \mathrm{m}^{3}$ increment of particulate matter $\left(\mathrm{PM}_{10}\right.$ and $\left.\mathrm{PM}_{2.5}\right)$ [4]. Similarly, CVD hospital admissions are reported to increase with the level of pollution $[5,6]$. A recent meta-analysis concluded that the risk of myocardial infarction (MI) increases significantly with all air pollutants screened, except for ozone [7]. In a comparative risk assessment, given its nature of unavoidable exposure, it is not surprising that the fraction of MI cases attributable to traffic is the highest among the known triggers of MI [8].

One of the plausible mechanisms to explain the causal link between exposure to air pollution and increased CVD mortality and hospital admissions is through an adverse effect of inhaled pollutants on the cardiac autonomic control $[9,10]$. Previous studies showed that $\mathrm{PM}_{2.5}$ exposure was associated with increased heart rate and decreased heart rate variability [11], both markers of autonomic 
dysfunction [12]. Impaired autonomic modulation may cause the onset of premature ventricular or atrial contractions [11], two common forms of arrhythmia. Additionally, early studies on patients with implantable cardioverter-defibrillators (ICDs) suggested that ventricular arrhythmias were the main causes of severe cardiovascular complications of exposure to air pollution [9].

Recent studies also suggested the possible association of air pollution exposure with atrial fibrillation (AF), the most frequent cardiac arrhythmia diagnosed in clinical practice [13]. The prevalence of AF in the general population increases with age, being around $1 \%$ or less in adults younger than 60 years and reaching $>9 \%$ in patients aged 80 or older [14,15]. Projected estimates point to a $>2$ fold increase of the number of AF patients by the year 2050 in both the US [15] and Europe [14]. In addition to the altered cardiac autonomic control [16-18], AF onset may be triggered by inflammation and oxidative stress $[19,20]$ and atrial pressure changes [21] which can all be linked to air pollution exposure [10].

In this paper, we hypothesized that the increase of air pollution levels is associated with increased AF emergency hospital visits. This hypothesis is assessed through the study of 14 years' time series of daily AF hospital emergency visits and pollution levels registered in the city of Rome. Because the AF may result from the cumulative effect of exposure events of different intensities sustained in the past, depending on the specific pollutant and of the physiological mechanisms linking the exposure to the outcome, we explored immediate (within 1 day), delayed ( $2-5$ days), or extended (cumulative effect of $0-5$ days) response of AF emergency hospital visits to the increase of pollution levels after adjusting for several time-varying covariates. Additionally, we studied the influence of pre-existing medical conditions as effect modifiers.

\section{Methods}

\subsection{Study Population}

The Rome municipality extends for $1287.36 \mathrm{~km}^{2}$ and had a registered population of 2,612,068 inhabitants during the 2001 census. Anonymous records for patients $\geq 35$ years, with a ICD-9 code 427.31 (atrial fibrillation) as the primary diagnosis, have been extracted from the administrative database recording all emergency visits in the period from 1 January 2001 to 31 December 2014, registered from 51 Emergency Departments of hospitals in Rome. Individuals residing outside the city boundaries were excluded from the population in order to increase the likelihood that exposure corresponded with the measured air pollution.

\subsection{Environmental Data}

Hourly nitrogen dioxide $\left(\mathrm{NO}_{2}\right)$, and particulate matter with diameter of $\leq 10 \mu \mathrm{m}\left(\mathrm{PM}_{10}\right)$ and of $\leq 2.5 \mu \mathrm{m}\left(\mathrm{PM}_{2.5}\right)$ levels were obtained from official online databases (ARPA Lazio, Regional Agency of Environmental Protection of the Lazio region). All data referred to hourly measurements and passed the quality control of the agency. $\mathrm{PM}_{2.5}$ data were available only for the period from 2006 to 2014 . Only monitors with $75 \%$ yearly data coverage were considered eligible [22] and suburban monitors were preferred to traffic-pollution monitors. Exposure was defined as the average of daily mean concentrations by three fixed eligible monitors. Missing values for each pollutant on a specific day and monitor were imputed with the average measurements of that pollutant for that day from the other monitors, weighted by the ratio of the yearly average at that monitor over the yearly average at the other monitoring stations for the same pollutant [23]. Average daily meteorological variables (temperature, barometric pressure, and dew-point temperature) at one station in central Rome were obtained from the Air Force monitoring network. We combined information from the air temperature and dew-point temperature to obtain an apparent temperature (AT) [24], an index of human discomfort, because it was demonstrated to have a stronger effect on health outcomes than the air temperature $[25,26]$. AT was calculated by the formula: AT $=-2.653+(0.994 \times \mathrm{Ta})+(0.0153 \times \mathrm{Td} 2)$, where Ta is the air temperature and $\mathrm{Td}$ is the dew point temperature [26]. 


\subsection{Statistical Analysis}

We performed a time-series analysis using conditional quasi-Poisson regression models, which is a flexible alternative to case-crossover design and provides comparable estimates to classic quasi-Poisson and case-crossover models [27], but allows for an important computational improvement of the time requested for statistical analysis. Time trend effects were controlled by inserting three-way interaction terms between the year, month, and day of the week. As we aimed at evaluating a possible association between the short-term concentration levels of pollutants and acute episodes of AF, we used moving averages of $\mathrm{PM}_{10}, \mathrm{PM}_{2.5}$, and $\mathrm{NO}_{2}$ at lags from 0 to 5 days. Following the current nomenclature, we defined immediate (from day 0 to day 1), delayed (from day 2 to day 5), and extended (from day 0 to day 5) effects to air pollution [28]. Besides the pollution and the time terms, predictor variables included in the model were apparent temperature (linear and quadratic terms), barometric pressure (linear and quadratic terms), and indicator variables for influenza epidemics, holiday periods, and a dummy for summer population decrease. In the exploratory analysis, models fitted with natural cubic splines with three degrees of freedom for apparent temperature did not have smaller values of the Akaike's Information Criterion compared to models fitted with linear and quadratic terms. Following similar studies conducted in Rome [28,29], we adjusted the model for warm temperatures by calculating the apparent temperature above the median of the whole study period at lag $0-1$ day and we adjusted for cold temperatures by calculating the apparent temperature below the median of the whole study period at lag 1-6 days. Two time-varying confounders were included in the analysis: influenza epidemics and holiday periods. Similar to other studies [30], we defined the population decrease during holidays as a 3 level variable assuming values " 0 " for working days, " 1 " for other non-working days like Labor Day, and "2" representing Christmas, Easter, and summer multiple days' vacation periods. The influenza peak period was defined as a variable with two possible levels where " 1 " represents the 3 weeks when the influenza incidence is peaking, and " 0 " for all other weeks [30]. The main model was also stratified for sex and age ( $<75 ; \geq 75$ years).

We used an individual approach using a logistic regression model to assess a possible effect modification following the case-only approach [31,32] that is suitable for modifiers that do not vary (personal characteristics), or do vary slowly (pre-existing chronic medical conditions) with the exposure of interest (e.g., pollution levels). This approach has the advantage, over traditional analyses (e.g., including several interaction terms in the main Poisson model), of simplifying the model specification [33]. Those individual data were available only for a single hospital (Policlinico Umberto I) and for a restricted time period (2001-2010), which represented $16.8 \%$ of all AF emergency visits registered in the same period in hospitals with comparable levels of emergency service (level 2 surgery). We evaluated a possible effect modification for: sex, age-category ( $<75$ and $>75$ years old), and pre-existing medical conditions defined as binary variables: diabetes (ICD-9: 250), cardiovascular diseases (previous heart failure ICD-9: 428; cardiac dysrhythmias ICD-9: 427; myocardial infarction ICD-9: 410; stroke ICD-9: 434), chronic respiratory disease (ICD-9: 490-492, 496), and other chronic diseases (including liver ICD-9: 571; kidneys ICD-9: 585; oncological ICD-9: 140-239 and neurodegenerative diseases ICD-9: 331). We fitted separate logistic regression models with $\mathrm{PM}_{10}, \mathrm{PM}_{2.5}$, and $\mathrm{NO}_{2}$ as predictors and the presence or absence of the hypothesized modifying condition as the dependent variable in the case data series. Moreover, we controlled for long-term and seasonal trends including a term for seasonal effect (sine and cosine terms with a 365.24-day period), as described in detail elsewhere [32]. The resulting coefficients provide an estimate of the change in the incremental effect of pollution in the group holding the modifying condition compared to others [33].

Finally, we produced a sensitivity analysis to assess the potential concomitant effects of multi-exposure through bi-pollutant models for $\mathrm{PM}_{10}, \mathrm{PM}_{2.5}$, and $\mathrm{NO}_{2}$. We included, in the models of the main analysis, the other pollutant in turn at the same cumulative lag. Additionally, the association between air pollution and AF emergency visits was also assessed by distributed lag non-linear models (DLNM) $[34,35]$ using the DLNM R package [36]. DLNM describes simultaneous non-linear and 
delayed effects of air pollution on hospital emergency visits. We fitted a linear function for air pollution and a spline function with 2 knots for the lag.

The results are reported as percent variation in the occurrence of emergency visits per a $10 \mu \mathrm{g} / \mathrm{m}^{3}$ increase in $\mathrm{PM}_{10}, \mathrm{PM}_{2.5}$, and $\mathrm{NO}_{2}$. For the case-only analysis, we reported results as interaction rate ratios (IRRs) estimating the Risk Ratios (RRs) for AF occurrence per $10 \mu \mathrm{g} / \mathrm{m}^{3}$ increases of pollutant concentration in persons who held the medical condition compared to persons who did not have the medical condition.

All analyses were performed with R software [37].

\section{Results}

In total, during the period from 2001 to 2014, 79,892 individuals were admitted to emergency departments of Rome hospitals because of $\mathrm{AF}$ (on average, 15.6 patients per day: $\min =1$, $\max =36$; Table 1$)$. Men represented $45.6 \%$ with a median age of 72 years $(\min 35, \max =100)$, while the median age of women was 74 years $(\min =35, \max =104)$. Summary statistics for air pollution, temperature, and relative humidity are reported in Table 1 . As expected, the mean daily levels of different pollutants were correlated ( $\mathrm{r}$ Pearson $\mathrm{PM}_{10}-\mathrm{NO}_{2}=0.60, \mathrm{PM}_{2.5}-\mathrm{PM}_{10}=0.88, \mathrm{PM}_{2.5}-\mathrm{NO}_{2}=0.68$ ).

Table 1. Summary statistics of daily exposure and number of emergency visits for atrial fibrillation (AF) in Rome in the 2001-2014 period.

\begin{tabular}{cccccc}
\hline Variables & N (Days) & Mean & SD & Min & Max \\
\hline $\mathrm{PM}_{10}$ & 5111 & 34.5 & 15.1 & 4.0 & 181.7 \\
$\mathrm{PM}_{2.5}$ & 3272 & 18.7 & 10.0 & 0.0 & 72.6 \\
$\mathrm{NO}_{2}$ & 5110 & 58.3 & 16.9 & 11.9 & 117.9 \\
Temperature & 5041 & 15.9 & 7.0 & -1.0 & 31.0 \\
Relative humidity & 4360 & 74.4 & 12.1 & 31.0 & 98.6 \\
Emergency visits for AF & 5113 & 15.6 & 4.9 & 1.0 & 36.0 \\
\hline
\end{tabular}

Table 2 presents the effect of air pollution on emergency visits for $\mathrm{AF}$ at different lags. Considering the whole sample, we found statistically significant associations between $\mathrm{PM}_{10}, \mathrm{PM}_{2.5}, \mathrm{NO}_{2}$, and $\mathrm{AF}$ visits at immediate lags, but not at delayed or extended lags. At immediate lags, the greatest effect estimate was observed for $\mathrm{PM}_{2.5}\left(2.95 \% ; 95 \%\right.$ CI: 1.35, 4.67\%), followed by $\mathrm{PM}_{10}(1.44 \%$; $95 \%$ CI: 0.65 , $2.26 \%$ ), and $\mathrm{NO}_{2}(1.19 \%$; $95 \% \mathrm{CI}: 0.27,2.13 \%)$. Those associations were greater for 75 years old or older patients with an estimated effect of 5.01\% (95\% CI: 2.59, 7.74\%) for $\mathrm{PM}_{2.5}, 2.70 \%$ (95\% CI: 1.42 , $4.07 \%$ ) for $\mathrm{PM}_{10}$, and 1.50 (95\% CI: $\left.0.03,3.02 \%\right)$ for $\mathrm{NO}_{2}$. In this age group a significant effect of $\mathrm{PM}_{2.5}$ at extended lag was also present (3.43\%; 95\% CI: 0.42, 6.66\%). Gender specific associations were generally greater for men, being significant for $\mathrm{PM}_{10}$ at immediate (1.51\%; $\left.95 \% \mathrm{CI}: 0.15,2.91 \%\right)$ and extended lags (1.87\%; $95 \%$ CI: $0.15,3.64 \%)$ and for $\mathrm{NO}_{2}$ at delayed $(1.83 \% ; 95 \%$ CI: $0.10,3.62 \%)$ and extended lags ( $2.40 \% ; 95 \%$ CI: $0.35,4.55 \%)$. The only significant association between pollution levels and emergency visits for $\mathrm{AF}$ for women was with $\mathrm{PM}_{2.5}$ at immediate lag (3.51\%; 95\% CI: $\left.1.29,5.90 \%\right)$. In bi-pollutant models, the effects of $\mathrm{PM}_{10}$ and $\mathrm{PM}_{2.5}$ with $\mathrm{NO}_{2}$ in the model on $\mathrm{AF}$ visits were weaker but significant at immediate lag, while the effects of $\mathrm{NO}_{2}$ (with $\mathrm{PM}_{10}$ and $\mathrm{PM}_{2.5}$ ) were not significant at all lags investigated (Table S1). Coherently with the main analysis, the DLNM analysis resulted in effect coefficients of similar size at lag 0-1 day (Supplementary Figures S1-S3). 
Table 2. Association between AF emergency visits and air pollution levels in fully adjusted models. Reported statistics are the percent increase in the risk of AF admission per $10 \mu \mathrm{g} / \mathrm{m}^{3}$ increase of pollutant $(95 \% \mathrm{CI})$.

\begin{tabular}{ccccc}
\hline Pollutant & Selection & Immediate (Lag 0-1) & Delayed (Lag 2-5) & Extended (Lag 0-5) \\
\hline \multirow{4}{*}{$\mathrm{PM}_{10}$} & All & $1.44(0.65,2.26)^{*}$ & $-0.04(-0.89,0.81)$ & $0.70(-0.30,1.72)$ \\
& $<75$ years & $0.66(-0.39,1.72)$ & $-0.12(-1.24,1.02)$ & $0.26(-1.07,1.60)$ \\
& $\geq 75$ years & $2.70(1.42,4.07)^{*}$ & $-0.04(-1.43,1.38)$ & $1.39(-0.27,3.09)$ \\
& Men & $1.51(0.15,2.91)^{*}$ & $1.17(-0.29,2.65)$ & $1.87(0.15,3.64)^{*}$ \\
& Women & $1.15(-0.13,2.47)$ & $-1.28(-2.63,0.11)$ & $-0.57(-2.18,1.06)$ \\
\hline & All & $2.95(1.35,4.67)^{*}$ & $0.13(-1.49,1.78)$ & $1.70(-0.29,3.76)$ \\
$\mathrm{PM}_{2.5}$ & $<75$ years & $1.44(-0.63,3.56)$ & $-0.45(-2.52,1.67)$ & $0.43(-2.10,3.03)$ \\
& $\geq 75$ years & $5.01(2.59,7.74)^{*}$ & $0.93(-1.53,3.47)$ & $3.43(0.42,6.66)^{*}$ \\
& Men & $2.31(-0.02,4.75)$ & $0.48(-1.87,2.90)$ & $1.59(-1.27,4.56)$ \\
& Women & $3.51(1.29,5.90)^{*}$ & $-0.18(-2.38,2.08)$ & $1.77(-0.96,4.61)$ \\
\hline \multirow{4}{*}{$\mathrm{NO}_{2}$} & All & $1.19(0.27,2.13)^{*}$ & $0.44(-0.57,1.47)$ & $1.10(-0.11,2.34)$ \\
& $<75$ years & $1.09(-0.12,2.33)$ & $0.09(-1.25,1.44)$ & $0.70(-0.89,2.33)$ \\
& $\geq 75$ years & $1.50(0.03,3.02)^{*}$ & $0.73(-0.90,2.39)$ & $1.57(-0.37,3.57)$ \\
& Men & $1.17(-0.39,2.77)$ & $1.83(0.10,3.62)^{*}$ & $2.40(0.35,4.55)^{*}$ \\
& Women & $0.89(-0.58,2.40)$ & $-1.12(-2.73,0.52)$ & $-0.54(-2.47,1.43)$ \\
\hline
\end{tabular}

Table 3 shows the analysis of effect modification in the subset of patients with detailed medical records (see Supplementary Table S2). The effects of $\mathrm{PM}_{10}$ and $\mathrm{NO}_{2}$ (but not of $\mathrm{PM}_{2.5}$ ) on AF visits were 6-9\% higher in individuals with previous CVD conditions (Table 3). All other pre-existing medical conditions were not significant modifiers of the pollution effects, although increasing patterns were apparent for chronic respiratory disease with $\mathrm{NO}_{2}$ (not significant effect increases of 3-6\%, Table 3).

Table 3. Effect modification of pre-existing medical conditions on the effect of $\mathrm{PM}_{10}, \mathrm{PM}_{2.5}$, and $\mathrm{NO}_{2}$ on AF emergency hospital visits. Results are expressed as interaction rate ratios (IRRs) per $10 \mu \mathrm{g} / \mathrm{m}^{3}$ increase of pollutant.

\begin{tabular}{cccccc}
\hline Pollutant & Lag & Diabetes & $\begin{array}{c}\text { Cardiovascular } \\
\text { Disease }\end{array}$ & $\begin{array}{c}\text { Chronic Respiratory } \\
\text { Disease }\end{array}$ & $\begin{array}{c}\text { Oncological, Liver, Renal, or } \\
\text { Neurodegenerative Disease }\end{array}$ \\
\hline \multirow{2}{*}{$\mathrm{PM}_{10}$} & $0-1$ & $0.98(0.91,1.06)$ & $1.06(1.00,1.12)^{*}$ & $0.97(0.89,1.05)$ & $0.99(0.94,1.05)$ \\
& $2-5$ & $1.04(0.96,1.13)$ & $1.07(1.00,1.14)^{*}$ & $1.01(0.92,1.11)$ & $0.97(0.91,1.04)$ \\
& $0-5$ & $1.02(0.93,1.12)$ & $1.09(1.01,1.17)^{*}$ & $0.99(0.89,1.10)$ & $0.97(0.91,1.05)$ \\
\hline \multirow{2}{*}{$\mathrm{PM}_{2.5}$} & $0-1$ & $0.93(0.80,1.07)$ & $1.08(0.98,1.19)$ & $0.99(0.85,1.15)$ & $1.03(0.93,1.14)$ \\
& $2-5$ & $1.02(0.88,1.18)$ & $1.05(0.95,1.17)$ & $0.97(0.82,1.14)$ & $0.99(0.89,1.11)$ \\
& $0-5$ & $1.00(0.84,1.19)$ & $1.10(0.97,1.25)$ & $0.96(0.79,1.16)$ & $1.03(0.90,1.17)$ \\
$\mathrm{NO}_{2}$ & $0-1$ & $0.99(0.92,1.06)$ & $1.07(1.01,1.13) *$ & $1.06(0.98,1.15)$ & $0.98(0.93,1.04)$ \\
& $2-5$ & $1.00(0.93,1.08)$ & $1.06(1.00,1.12)^{*}$ & $1.03(0.94,1.13)$ & $0.97(0.92,1.03)$ \\
& $0-5$ & $0.99(0.91,1.08)$ & $1.08(1.01,1.15) *$ & $1.05(0.96,1.16)$ & $0.97(0.91,1.04)$ \\
\hline \multicolumn{5}{c}{}
\end{tabular}

\section{Discussion}

Atrial fibrillation is the most common arrhythmia encountered in clinical practice and AF patients may present general symptomatology such as chest pain, palpitations, and dyspnea [38]. Although it has a high incidence in the population, the underlying mechanisms responsible for induction and perpetuation of AF remain incompletely understood [39]. Altered cardiac autonomic control, inflammation and oxidative stress, and atrial blood pressure changes are among the mechanisms suggested for AF onset [40]. We found that higher concentrations of air pollution may trigger AF emergency visits in the short term. The effect is particularly consistent with increasing $\mathrm{PM}_{2.5}$ concentration at $0-1$ day lag, with effects ranging from nearly a 3\% increase of hospital visits for AF for 
the whole sample to $5 \%$ for individuals $\geq 75$ years. We also found significant effects at lag $0-1$ day for $\mathrm{PM}_{10}$ and $\mathrm{NO}_{2}$. The results of the models stratified by age category confirmed the higher sensitivity of subjects $\geq 75$ years of age as observed for hospitalizations for other cardiac causes, while the results stratified by sex were less consistent.

Epidemiological evidence of the air pollution effect on AF onset is contradictory. Studies on patients with implantable cardioverter-defibrillators reported increased AF risk with increasing ozone $\left(\mathrm{O}_{3}\right)$ [41,42], $\mathrm{NO}_{2}$ [43], $\mathrm{PM}_{2.5}$ [44], and sulfate $\left(\mathrm{SO}_{4}\right)$ [42]. However, no associations were also reported with $\mathrm{PM}_{2.5}$ [45], $\mathrm{NO}_{2}$, carbon monoxide (CO), sulphur dioxide $\left(\mathrm{SO}_{2}\right)[45,46]$, black carbon, $\mathrm{SO}_{4}$, and $\mathrm{O}_{3}$ [46]. A recent study on individuals that referred to a $24 \mathrm{~h}$ period of ambulatory cardiac monitoring did not find a significant increase of $\mathrm{AF}$ events with $\mathrm{NO}_{2}$ and $\mathrm{PM}_{2.5}$, possibly because of the relative low levels of pollution in the study area [47]. Results of the association between AF and air pollution are also not consistent in population based studies. For example, Sade et al. examined 1458 hospital admissions for new-onset $\mathrm{AF}$ and found a significant association with $\mathrm{CO}, \mathrm{NO}_{2}$, and $\mathrm{SO}_{2}$, but not with $\mathrm{PM}_{10}$ and $\mathrm{O}_{3}$ [48]. Similarly, a UK study examined $>2$ million of CVD emergency hospital admissions and found significant association of $\mathrm{AF}$ with $\mathrm{NO}_{2}$ but not $\mathrm{CO}, \mathrm{O}_{3}, \mathrm{PM}_{10}, \mathrm{PM}_{2.5}$ and $\mathrm{SO}_{2}$ [49]. $\mathrm{NO}_{2}$ derives from direct emissions of diesel vehicles and from secondary reactions of ozone with nitric oxide and typically has a spatial correlation with other combustion products (such as exhaust particles, carbon monoxide, and sulphur dioxide) emitted at the same time [50]. Therefore, the mixture of pollutants derived from exposure to traffic (for which $\mathrm{NO}_{2}$ is a marker) or $\mathrm{NO}_{2}$ by itself, might lead to chronic autonomic dysfunction through multiple pathways [4], increasing the risk of AF episodes. Notably, in a large population time-series study in the US on more than 10,000 people, no association between cumulative exposure to $\mathrm{PM}_{2.5}$ and acute episodes of $\mathrm{AF}$ was found [51], although the omission in the statistical model of important covariates could partially explain the result [50]. The latter argument might also explain the absence of association between the acute onset of AF and air pollution observed in a short time series study conducted in Italy [52].

In the case-only analysis, we found an increase of risk of AF emergency admission for subjects that had a previous medical examination or treatment because of cardiovascular problems. We found statistically significant results for $\mathrm{PM}_{10}$ and $\mathrm{NO}_{2}$ and marginally not significant results for $\mathrm{PM}_{2.5}$, possibly because of the low power used to detect a significant effect for the latter pollutant for which the monitoring data availability started in 2006. It is well documented that patients with previous episodes of major CVD events or that are suffering from chronic CVD have a higher probability of being re-hospitalized for the same or another cardiac complication [53]. In our analysis, up to $75 \%$ of individuals had prior history of CVDs and thus these individuals are at particularly high risk for AF, which may predict more serious and potentially life-threatening events such as stroke [38]. For example, a time-series study in Montreal conducted on more than 150,000 deaths of $>65$ years people, found a positive association between $\mathrm{NO}_{2}$ and $\mathrm{PM}_{2.5}$ and mortality percent change in individuals with a previous diagnosis of AF [54]. In a similar study in UK, among all pollutants, only $\mathrm{PM}_{2.5}$ was associated to AF as the primary cause of death in a large event database [49]. Also, an analysis of long term exposure to high ambient $\mathrm{NO}_{2}$ pointed to a higher susceptibility of subjects with an underlying cardiovascular disease [55].

As in many other time-series studies, several study limitations need to be addressed. First, our study assessed the association of AF with air pollution considering the date of emergency visits that may come after the time of AF onset by hours or days, potentially causing exposure misclassification. Another possible limitation that we have to point out relates to the information provided by the health regional databases using ICD-9 codes, so we cannot use a more modern and accurate classification such as ICD-10. However, we considered that a possible information bias due to less accuracy in ICD-9 codes could be non-differential, and therefore was not able to alter the estimates of association.

Since studies with ICDs have pointed out a very rapid response of AF to increases of pollution levels [46], by using emergency care patients and examining different short-term time lags, we possibly reduced the misclassification due to the different timing between the pollutant and the case series. 
Second, temporal variation of exposure was estimated through the time-series of pollution levels derived from within-city monitor measures, excluding surrounding towns and villages. Like in other studies, we could not apply individual exposures for cases, so we used the daily average levels from all air quality monitors with sufficient temporal coverage. We have excluded patients residing outside the city boundaries to increase the likelihood that temporal variation in exposure corresponded to the measured temporal variation of air pollution, but some misclassification of exposure might have occurred. Third, because of the large number of model runs ( 3 pollutant $\times 3$ lags), it is possible that some significant results might happen by chance only. Finally, the case-only analysis was based on a subset of total AF records coming from a single hospital and for a restricted time period, and the statistical power of this analysis was possibly lower for medical conditions with small occurrence in the sample.

\section{Conclusions}

Arrhythmias, of which AF is the most prevalent form, have been linked with major cardiovascular events such as ischemic stroke and heart failure. The deregulation of the autonomic nervous system and/or the inflammatory response are known causes of AF onset and are linked to pulmonary oxidative stress and inflammation following exposure to high levels of air pollutants. Our results add evidence to the fact that a high concentration of air pollution is associated with an increased number of people seeking emergency aid because of AF within $24 \mathrm{~h}$. The effect of increased $\mathrm{PM}_{10}$ and $\mathrm{NO}_{2}$ on AF admission was exacerbated in individuals with a previous history of CVD. Since people with AF have a 5-fold increased risk of stroke [56], even a modest risk associated with exposure to high levels of air pollution would largely increase the attributable risk in the general population.

Supplementary Materials: The following are available online at www.mdpi.com/1660-4601/14/6/661/s1, Figure S1: Relative risks of emergency room admission for atrial fibrillation associated with $\mathrm{PM}_{10}$ of $44.5 \mu \mathrm{g} / \mathrm{m}^{3}$ compared to a centered concentration of $\mathrm{PM}_{10}=34.5 \mu \mathrm{g} / \mathrm{m}^{3}$ (mean of the whole study period) on lag 0 to 5 in Rome during 2001-2014, Figure S2: Relative risks of emergency room admission for atrial fibrillation associated with $\mathrm{PM}_{2.5}$ of $28.7 \mu \mathrm{g} / \mathrm{m}^{3}$ compared to a centered concentration of $\mathrm{PM}_{2.5}=18.7 \mu \mathrm{g} / \mathrm{m}^{3}$ (mean of the whole study period) on lag 0 to 5 in Rome during 2001-2014, Figure S3: Relative risks of emergency room admission for atrial fibrillation associated with $\mathrm{NO}_{2}$ of $68.3 \mu \mathrm{g} / \mathrm{m}^{3}$ compared to a centered concentration of $\mathrm{NO}_{2}=58.3 \mu \mathrm{g} / \mathrm{m}^{3}$ (mean of the whole study period) on lag 0 to 5 in Rome during 2001-2014, Table S1: Bipollutant models of the association between AF emergency hospital admissions and air pollution levels. Reported statistics are the \% increase in risk per 10 unit increase of pollutant (95\% CI), Table S2: Pre-existing medical conditions in the consecutive case series coming from a single hospital from which those data were available $(n=4482$; only years 2006-2010). Median age was 72 years $(\min =45 ; \max =100)$; women represented $51.8 \%$ of total patients.

Acknowledgments: We thank B. Armstrong for suggestions on the interpretation of the results and sensitivity analysis. We also thank F. Forastiere for useful comments on an earlier draft of the manuscript, and thank Gianluca Pompei for proofreading the article.

Author Contributions: Angelo G. Solimini conceived the study, collected the data, carried out the statistical analysis, and wrote the article. Matteo Renzi collected the data, carried out the statistical analysis, and wrote part of the article.

Conflicts of Interest: The authors declare no conflict of interest.

\section{References}

1. Burgan, O.; Smargiassi, A.; Perron, S.; Kosatsky, T. Cardiovascular effects of sub-daily levels of ambient fine particles: A systematic review. Environ. Health 2010, 9, 26. [CrossRef] [PubMed]

2. Brook, R.D. Cardiovascular effects of air pollution. Clin. Sci. 2008, 115, 175-187. [CrossRef] [PubMed]

3. Dockery, D.W. Epidemiologic evidence of cardiovascular effects of particulate air pollution. Environ. Health Perspect. 2001, 109, 483-486. [CrossRef] [PubMed]

4. Brook, R.D.; Rajagopalan, S.; Pope, C.A.; Brook, J.R.; Bhatnagar, A.; Diez-Roux, A.V.; Holguin, F.; Hong, Y.; Luepker, R.V.; Mittleman, M.; et al. Particulate matter air pollution and cardiovascular disease: An update to the scientific statement from the American Heart Association. Circulation 2010, 121, 2331-2378. [CrossRef] [PubMed] 
5. Peng, R.D.; Chang, H.H.; Bell, M.L.; McDermott, A.; Zeger, S.L.; Samet, J.M.; Dominici, F. Coarse particulate matter air pollution and hospital admissions for cardiovascular and respiratory diseases among Medicare patients. JAMA 2008, 299, 2172-2179. [CrossRef] [PubMed]

6. Dominici, F.; Peng, R.D.; Bell, M.L.; Pham, L.; McDermott, A.; Zeger, S.L.; Samet, J.M. Fine particulate air pollution and hospital admission for cardiovascular and respiratory diseases. JAMA 2006, 295, 1127-1134. [CrossRef] [PubMed]

7. Mustafic, H.; Jabre, P.; Caussin, C.; Murad, M.H.; Escolano, S.; Tafflet, M.; Périer, M.-C.; Marijon, E.; Vernerey, D.; Empana, J.-P.; et al. Main air pollutants and myocardial infarction: A systematic review and meta-analysis. JAMA 2012, 307, 713-721. [CrossRef] [PubMed]

8. Nawrot, T.S.; Perez, L.; Künzli, N.; Munters, E.; Nemery, B. Public health importance of triggers of myocardial infarction: A comparative risk assessment. Lancet 2011, 377, 732-740. [CrossRef]

9. Routledge, H.C.; Ayres, J.G.; Townend, J.N. Why cardiologists should be interested in air pollution. Heart 2003, 89, 1383-1388. [CrossRef] [PubMed]

10. Watkins, A.; Danilewitz, M.; Kusha, M.; Massé, S.; Urch, B.; Quadros, K.; Spears, D.; Farid, T.; Nanthakumar, K. Air pollution and arrhythmic risk: The smog is yet to clear. Can. J. Cardiol. 2013, 29, 734-741. [CrossRef] [PubMed]

11. He, F.; Shaffer, M.L.; Rodriguez-Colon, S.; Yanosky, J.D.; Bixler, E.; Cascio, W.E.; Liao, D. Acute effects of fine particulate air pollution on cardiac arrhythmia: The APACR study. Environ. Health Perspect. 2011, 119, 927-932. [CrossRef] [PubMed]

12. Link, M.S.; Dockery, D.W. Air pollution and the triggering of cardiac arrhythmias. Curr. Opin. Cardiol. 2010, 25, 16-22. [CrossRef] [PubMed]

13. Whitsel, E.A.; Avery, C.L. The environmental epidemiology of atrial arrhythmogenesis. J. Epidemiol. Community Health 2010, 64, 587-590. [CrossRef] [PubMed]

14. Krijthe, B.P.; Kunst, A.; Benjamin, E.J.; Lip, G.Y.H.; Franco, O.H.; Hofman, A.; Witteman, J.C.M.; Stricker, B.H.; Heeringa, J. Projections on the number of individuals with atrial fibrillation in the European Union, from 2000 to 2060. Eur. Heart J. 2013, 34, 2746-2751. [CrossRef] [PubMed]

15. Go, A.S.; Hylek, E.M.; Phillips, K.A.; Chang, Y.; Henault, L.E.; Selby, J.V.; Singer, D.E. Prevalence of diagnosed atrial fibrillation in adults: National implications for rhythm management and stroke prevention: The AnTicoagulation and Risk Factors in Atrial Fibrillation (ATRIA) Study. JAMA 2001, 285, 2370-2375. [CrossRef] [PubMed]

16. Bettoni, M. Autonomic Tone Variations Before the Onset of Paroxysmal Atrial Fibrillation. Circulation 2002, 105, 2753-2759. [CrossRef] [PubMed]

17. Schauerte, P.; Scherlag, B.J.; Patterson, E.; Scherlag, M.A.; Matsudaria, K.; Nakagawa, H.; Lazzara, R.; Jackman, W.M. Focal atrial fibrillation: Experimental evidence for a pathophysiologic role of the autonomic nervous system. J. Cardiovasc. Electrophysiol. 2001, 12, 592-599. [CrossRef] [PubMed]

18. Zimmermann, M.; Kalusche, D. Fluctuation in autonomic tone is a major determinant of sustained atrial arrhythmias in patients with focal ectopy originating from the pulmonary veins. J. Cardiovasc. Electrophysiol. 2001, 12, 285-291. [CrossRef] [PubMed]

19. Aviles, R.J.; Martin, D.O.; Apperson-Hansen, C.; Houghtaling, P.L.; Rautaharju, P.; Kronmal, R.A.; Tracy, R.P.; Van Wagoner, D.R.; Psaty, B.M.; Lauer, M.S.; et al. Inflammation as a risk factor for atrial fibrillation. Circulation 2003, 108, 3006-3010. [CrossRef] [PubMed]

20. Chung, M.K.; Martin, D.O.; Sprecher, D.; Wazni, O.; Kanderian, A.; Carnes, C.A.; Bauer, J.A.; Tchou, P.J.; Niebauer, M.J.; Natale, A.; et al. C-Reactive Protein Elevation in Patients With Atrial Arrhythmias: Inflammatory Mechanisms and Persistence of Atrial Fibrillation. Circulation 2001, 104, 2886-2891. [CrossRef] [PubMed]

21. White, C.W.; Kerber, R.E.; Weiss, H.R.; Marcus, M.L. The effects of atrial fibrillation on atrial pressure-volume and flow relationships. Circ. Res. 1982, 51, 205-215. [CrossRef] [PubMed] 
22. Katsouyanni, K.; Schwartz, J.; Spix, C.; Touloumi, G.; Zmirou, D.; Zanobetti, A.; Wojtyniak, B.; Vonk, J.M.; Tobias, A.; Pönkä, A.; et al. Short term effects of air pollution on health: A European approach using epidemiologic time series data: The APHEA protocol. J. Epidemiol. Community Health 1996, 50 (Suppl. 1), S12-S18. [CrossRef] [PubMed]

23. Stafoggia, M.; Forastiere, F.; Faustini, A.; Biggeri, A.; Bisanti, L.; Cadum, E.; Cernigliaro, A.; Mallone, S.; Pandolfi, P.; Serinelli, M.; et al. Susceptibility factors to ozone-related mortality: A population-based case-crossover analysis. Am. J. Respir. Crit. Care Med. 2010, 182, 376-384. [CrossRef] [PubMed]

24. Stedman, R. The Assessment of Sultriness. Part I: A Temperature-Humidity Index Based on Human Physiology and Clothing Science. J. Appl. Meteorol. 1979, 18, 861-873. [CrossRef]

25. Kalkstein, L.; Valimont, K. An Evaluation of Summer Discomfort in the United State Using a Relative Climatological Index. Bull. Am. Meteorol. Soc. 1986, 67, 842-848. [CrossRef]

26. O'Neill, M.; Zanobetti, A.; Schwartz, J. Modifiers of the temperature and mortality association in seven US cities. Am. J. Epidemiol. 2003, 157, 1074-1082. [CrossRef] [PubMed]

27. Armstrong, B.G.; Gasparrini, A.; Tobias, A. Conditional Poisson models: A flexible alternative to conditional logistic case cross-over analysis. BMC Med. Res. Methodol. 2014, 14, 122. [CrossRef] [PubMed]

28. Faustini, A.; Stafoggia, M.; Colais, P.; Berti, G.; Bisanti, L.; Cadum, E.; Cernigliaro, A.; Mallone, S.; Scarnato, C.; Forastiere, F. Air pollution and multiple acute respiratory outcomes. Eur. Respir. J. 2013, 42, 304-313. [CrossRef] [PubMed]

29. Mallone, S.; Stafoggia, M.; Faustini, A.; Gobbi, P.; Marconi, A.; Forastiere, F. Saharan dust and associations between particulate matter and daily mortality in Rome, Italy. Environ. Health Perspect. 2011, 119, 1409-1414. [CrossRef] [PubMed]

30. Stafoggia, M.; Samoli, E.; Alessandrini, E.; Cadum, E.; Ostro, B.; Berti, G.; Faustini, A.; Jacquemin, B.; Linares, C.; Pascal, M.; et al. Short-term associations between fine and coarse particulate matter and hospitalizations in Southern Europe: Results from the MED-PARTICLES project. Environ. Health Perspect. 2013, 121, 1026-1033. [CrossRef] [PubMed]

31. Armstrong, B.G. Fixed factors that modify the effects of time-varying factors: Applying the case-only approach. Epidemiology 2003, 14, 467-472. [CrossRef] [PubMed]

32. Schwartz, J. Who is sensitive to extremes of temperature? A case-only analysis. Epidemiology 2005, 16, 67-72. [CrossRef] [PubMed]

33. Zanobetti, A.; O’Neill, M.S.; Gronlund, C.J.; Schwartz, J.D. Susceptibility to mortality in weather extremes: Effect modification by personal and small-area characteristics. Epidemiology 2013, 24, 809-819. [CrossRef] [PubMed]

34. Armstrong, B. Models for the relationship between ambient temperature and daily mortality. Epidemiology 2006, 17, 624-631. [CrossRef] [PubMed]

35. Gasparrini, A. Modeling exposure-lag-response associations with distributed lag non-linear models. Stat. Med. 2014, 33, 881-899. [CrossRef] [PubMed]

36. Gasparrini, A Distributed Lag Linear and Non-Linear Models in R: The Package dlnm. J. Stat. Softw. 2011, $43,2-20$.

37. R Development Core Team. A Language and Environment for Statistical Computing. R Found. Stat. Comput. 2011, 1, 409.

38. Camm, A.J.; Kirchhof, P.; Lip, G.Y.H.; Schotten, U.; Savelieva, I.; Ernst, S.; Van Gelder, I.C.; Al-Attar, N.; Hindricks, G.; Prendergast, B.; et al. Guidelines for the management of atrial fibrillation: The Task Force for the Management of Atrial Fibrillation of the European Society of Cardiology (ESC). Eur. Heart J. 2010, 31, 2369-2429. [PubMed]

39. Dewland, T.A.; Olgin, J.E.; Vittinghoff, E.; Marcus, G.M. Incident atrial fibrillation among Asians, Hispanics, blacks, and whites. Circulation 2013, 128, 2470-2477. [CrossRef] [PubMed]

40. Link, M.S.; Luttmann-Gibson, H.; Schwartz, J.; Mittleman, M.A.; Wessler, B.; Gold, D.R.; Dockery, D.W.; Laden, F. Reply: Triggering of cardiac arrhythmias: The problem of multicollinearity among air pollution and meteorological factors. J. Am. Coll. Cardiol. 2014, 63, 1227-1228. [CrossRef] [PubMed]

41. Rich, D.Q.; Schwartz, J.; Mittleman, M.A.; Link, M.; Luttmann-Gibson, H.; Catalano, P.J.; Speizer, F.E.; Dockery, D.W. Association of short-term ambient air pollution concentrations and ventricular arrhythmias. Am. J. Epidemiol. 2005, 161, 1123-1132. [CrossRef] [PubMed] 
42. Sarnat, S.E.; Suh, H.H.; Coull, B.A.; Schwartz, J.; Stone, P.H.; Gold, D.R. Ambient particulate air pollution and cardiac arrhythmia in a panel of older adults in Steubenville, Ohio. Occup. Environ. Med. 2006, 63, 700-706. [CrossRef] [PubMed]

43. Peters, A.; Liu, E.; Verrier, R.L.; Schwartz, J.; Gold, D.R.; Mittleman, M.; Baliff, J.; Oh, J.A.; Allen, G.; Monahan, K.; et al. Air pollution and incidence of cardiac arrhythmia. Epidemiology 2000, 11, 11-17. [CrossRef] [PubMed]

44. Liao, D.; Shaffer, M.L.; He, F.; Rodriguez-Colon, S.; Wu, R.; Whitsel, E.A.; Bixler, E.O.; Cascio, W.E. Fine particulate air pollution is associated with higher vulnerability to atrial fibrillation-The APACR study. J. Toxicol. Environ. Health. A 2011, 74, 693-705. [CrossRef] [PubMed]

45. Rich, D.Q.; Mittleman, M.A.; Link, M.S.; Schwartz, J.; Luttmann-Gibson, H.; Catalano, P.J.; Speizer, F.E.; Gold, D.R.; Dockery, D.W. Increased Risk of Paroxysmal Atrial Fibrillation Episodes Associated with Acute Increases in Ambient Air Pollution. Environ. Health Perspect. 2006, 114, 120-123. [CrossRef] [PubMed]

46. Link, M.S.; Luttmann-Gibson, H.; Schwartz, J.; Mittleman, M.A.; Wessler, B.; Gold, D.R.; Dockery, D.W.; Laden, F. Acute exposure to air pollution triggers atrial fibrillation. J. Am. Coll. Cardiol. 2013, 62, 816-825. [CrossRef] [PubMed]

47. Cakmak, S.; Kauri, L.; Shutt, R.; Liu, L.; Green, M.S.; Mulholland, M.; Stieb, D.; Dales, R. The association between ambient air quality and cardiac rate and rhythm in ambulatory subjects. Environ. Int. 2014, 73, 365-371. [CrossRef] [PubMed]

48. Yitshak Sade, M.; Vodonos, A.; Novack, V.; Friger, M.; Amit, G.; Katra, I.; Schwartz, J.; Novack, L. Can air pollution trigger an onset of atrial fibrillation: A population-based study. Air Qual. Atmos. Health 2015, 8, 413-420. [CrossRef]

49. Milojevic, A.; Wilkinson, P.; Armstrong, B.; Bhaskaran, K.; Smeeth, L.; Hajat, S. Short-term effects of air pollution on a range of cardiovascular events in England and Wales: Case-crossover analysis of the MINAP database, hospital admissions and mortality. Heart 2014, 100, 1093-1098. [CrossRef] [PubMed]

50. Samoli, E.; Aga, E.; Touloumi, G.; Nisiotis, K.; Forsberg, B.; Lefranc, A.; Pekkanen, J.; Wojtyniak, B.; Schindler, C.; Niciu, E.; et al. Short-term effects of nitrogen dioxide on mortality: An analysis within the APHEA project. Eur. Respir. J. 2006, 27, 1129-1138. [CrossRef] [PubMed]

51. Bunch, T.J.; Horne, B.D.; Asirvatham, S.J.; Day, J.D.; Crandall, B.G.; Weiss, J.P.; Osborn, J.S.; Anderson, J.L.; Muhlestein, J.B.; Lappe, D.L.; et al. Atrial fibrillation hospitalization is not increased with short-term elevations in exposure to fine particulate air pollution. Pacing Clin. Electrophysiol. 2011, 34, 1475-1479. [CrossRef] [PubMed]

52. Cervellin, G.; Comelli, I.; Lippi, G. Lack of correlation between air pollution and acute-onset atrial fibrillation. Can. J. Cardiol. 2013, 29, 1743. [CrossRef] [PubMed]

53. Colais, P.; Faustini, A.; Stafoggia, M.; Berti, G.; Bisanti, L.; Cadum, E.; Cernigliaro, A.; Mallone, S.; Pacelli, B.; Serinelli, M.; et al. Particulate air pollution and hospital admissions for cardiac diseases in potentially sensitive subgroups. Epidemiology 2012, 23, 473-481. [CrossRef] [PubMed]

54. Goldberg, M.S.; Burnett, R.T.; Stieb, D.M.; Brophy, J.M.; Daskalopoulou, S.S.; Valois, M.-F.; Brook, J.R. Associations between ambient air pollution and daily mortality among elderly persons in Montreal, Quebec. Sci. Total Environ. 2013, 463-464, 931-942. [CrossRef] [PubMed]

55. Felber Dietrich, D.; Gemperli, A.; Gaspoz, J.-M.; Schindler, C.; Liu, L.-J.S.; Gold, D.R.; Schwartz, J.; Rochat, T.; Barthélémy, J.-C.; Pons, M.; et al. Differences in heart rate variability associated with long-term exposure to $\mathrm{NO}_{2}$. Environ. Health Perspect. 2008, 116, 1357-1361. [CrossRef] [PubMed]

56. Ryder, K.M.; Benjamin, E.J. Epidemiology and significance of atrial fibrillation. Am. J. Cardiol. 1999, 84, 131R-138R. [CrossRef]

(C) 2017 by the authors. Licensee MDPI, Basel, Switzerland. This article is an open access article distributed under the terms and conditions of the Creative Commons Attribution (CC BY) license (http:/ / creativecommons.org/licenses/by/4.0/). 